\title{
How the Blockchain Enables and Constrains Supply Chain Performance
}

Hald, Kim Sundtoft; Kinra, Aseem

\author{
Document Version \\ Accepted author manuscript \\ Published in: \\ International Journal of Physical Distribution \& Logistics Management
}

DOI:

10.1108/IJPDLM-02-2019-0063

Publication date:

2019

License

Unspecified

Citation for published version (APA):

Hald, K. S., \& Kinra, A. (2019). How the Blockchain Enables and Constrains Supply Chain Performance. International Journal of Physical Distribution \& Logistics Management, 49(4), 376-397.

https://doi.org/10.1108/IJPDLM-02-2019-0063

Link to publication in CBS Research Portal

\section{General rights}

Copyright and moral rights for the publications made accessible in the public portal are retained by the authors and/or other copyright owners and it is a condition of accessing publications that users recognise and abide by the legal requirements associated with these rights.

\section{Take down policy}

If you believe that this document breaches copyright please contact us (research.lib@cbs.dk) providing details, and we will remove access to the work immediately and investigate your claim. 


\section{How the Blockchain Enables and Constrains Supply Chain Performance}

\section{Kim Sundtoft Hald and Aseem Kinra}

Journal article (Accepted manuscript*)

\section{Please cite this article as:}

Hald, K. S., \& Kinra, A. (2019). How the Blockchain Enables and Constrains Supply Chain Performance. International Journal of Physical Distribution \& Logistics Management, 49(4), 376-397. https://doi.org/10.1108/IJPDLM-02-2019-0063

\section{DOI: 10.1108/IJPDLM-02-2019-0063}

This article is (5) Emerald Group Publishing and permission has been granted for this version to appear here: https://research.cbs.dk/en/publications/how-the-blockchain-enables-and-constrains-supply-chainperformanc.

Emerald does not grant permission for this article to be further copied/distributed or hosted elsewhere without the express permission from Emerald Group Publishing Limited.

* This version of the article has been accepted for publication and undergone full peer review but has not been through the copyediting, typesetting, pagination and proofreading process, which may lead to differences between this version and the publisher's final version AKA Version of Record. 


\title{
How the blockchain enables and constrains supply chain performance ${ }^{1}$
}

\author{
Kim Sundtoft Hald \\ Professor (mso) \\ Copenhagen Business School, Department of Operations Management \\ Solbjerg Plads 3, 2000 Frederiksberg, Denmark \\ Tel: +4523722303 \\ E-mail:ksh.om@cbs.dk \\ Aseem Kinra \\ Associate Professor \\ Copenhagen Business School, Department of Operations Management \\ Solbjerg Plads 3, 2000 Frederiksberg, Denmark \\ Tel: +4538153529 \\ E-mail: aki.om@cbs.dk
}

\begin{abstract}
Purpose - The purpose of this paper is to understand the enabling and constraining roles of blockchain technology in managerial work practices and to conceptualise the technologyperformance relationship in supply chain management.

Design/methodology/approach - A structured literature review and a theory-driven approach are used. A set of propositions are developed, suggesting how the use of blockchain technology in supply chains can be understood to simultaneously enable and constrain supply chain management and performance.

Findings - The analysis identifies four enabling and three constraining blockchain identities to explain how the technology either 'facilitates' or 'impedes' supply chain management and supply chain performance. Traceability which emanates from its ability to provide data immutability ranks highly as a core innovation of the technology. The blockchain is mainly seen as an opportunity to exploit existing supply chain resources and competencies.

Research limitations/implications - One limitation of the research is its conceptual nature. Future research should test the developed propositions empirically. Further research should focus on blockchain technology as an opportunity to explore and as a relationship-building technology. More research is also needed focussing on the complex and simultaneous enabling and constraining effects of blockchain technology in supply chains.

Originality/value - The paper shows the important and complex Janus-faced implications of embedding blockchain technology in supply chains and demonstrates how organisational theory can be applied to explore the relationship between blockchain and supply chain management.
\end{abstract}

Keywords Blockchain technology, distributed computing, supply chain performance, supply chain management, enabling and constraining effects.

Paper type Research paper.

\footnotetext{
${ }^{1}$ For citation to this work please use: Hald, K. S. and Kinra, A. (2019) 'How the blockchain enables and constrains supply chain performance', International Journal of Physical Distribution \& Logistics Management, 49(4), pp. 376-397.
} 


\section{INTRODUCTION}

Blockchain technology (BCT) is gaining momentum, with an increasing number of diverse applications, as well as with more and more actors involved in its applications (Nowiński and Kozma, 2017). It is one of the select, emerging technologies which is expected to enable transformational platform-based business models to enhance competitive advantages (Burkett and Johnson, 2016). Popularly hailed as 'the most important invention since the Internet' (Tapscott and Tapscott, 2016a), BCT has been identified as one of the top ten strategic technology trends (Panetta, 2016). With mainstream adoption of the technology expected within five to ten years, it will be possible to see its widespread applications in terms of monetary remittances, academic credential systems, land title systems, tracking the origin and provenance of products and many more areas (Panetta, 2017). The technology is expected to have profound and disruptive effects on society as a whole and has therefore triggered an international policy response calling for a joint technological infrastructure (Pedersen, 2018).

With the global blockchain in the supply chain market poised to reach USD 424 million by the year 2023 (Dyble, 2018), academic and practitioner interest from a supply chain management (SCM) perspective is also growing exponentially (Kshetri, 2018). Blockchains within SCM have been addressed by case descriptions of its use or potential use in different industrial settings. Blockchains in the food industry (e.g., Coyne, 2017; Yuva, 2017), the shipping industry (e.g., Riley, 2017; Tirschwell, 2018), and the pharmaceutical/healthcare industry (e.g., Bocek et al., 2017; Shanley, 2017) have attracted the most attention.

However, knowledge generation on BCT within SCM is still very early in its lifecycle. Although some peer-reviewed publications on the relation between BCT and SCM have emerged, these emphasise the broader role of the blockchain in achieving supply chain competitive priorities at the organisational level (see Kshetri, 2018; Petersen et al., 2017). Another challenge is that the literature on BCT within SCM needs theoretical substance and a theoretical foundation, based on which it can begin a more structured process of knowledge generation. The current knowledge is dominated by a multitude of imprecise literature highlighting the many promises of the new technology. This is a problem, because the theoretical and methodological approaches of these contributions are weak and the validity of their claims low (Adams et al., 2017a). While some recent research on the theorisation of blockchain for SCM has emerged (see Treiblmaier, 2018), it has yet to conceptualise both the positive and negative managerial work-related effects of the technology and its specific architectural properties. As a result, the technology, management and performance relationship (Hald and Mouritsen, 2011) remains under-conceptualised.

This study explores the potentially enabling and constraining managerial implications of BCT for SCM. It addresses the impact of the technology on dimensions of SCM and supply chain performance. Because the technology affects not only supply chain processes but also individual actors and their behaviours, its impact on the supply chain can be complex, uncertain and potentially both enabling and constraining (Lyall et al., 2018). There is, therefore, a need for research which may establish a grand overview of this complexity and synthesise current insights into a set of propositions that highlight both the potentially enabling and constraining effects of this new technology.

The research presented in this paper makes several contributions. The theoretical approach and synthesis are new. Based on Adler and Borys (1996), the research takes into account the blockchain as an organisational technology which is seen as powerful and actively affecting the ability to manage the supply chain, its processes and its relationships. This adds to the literature, which has not yet explored how the same potentially powerful architectural properties of BCT might have both enabling and constraining effects for SCM and supply chain performance (see 
Treiblmaier, 2018). This adds a new and more holistic understanding of the potential dual implications of BCT on SCM.

The paper is structured as follows. Section 2 presents BCT and its relationship to SCM and performance. Section 3 describes the research methodology. Section 4 analyses the literature with a view towards its position on how BCT may enable and/or constrain SCM. Finally, the discussion and conclusion are presented in Section 5 and Section 6.

\section{BLOCKCHAIN TECHNOLOGY, SCM AND PERFORMANCE}

\subsection{Blockchain technology}

A blockchain can be defined as "a digital, decentralised and distributed ledger in which transactions are logged and added in chronological order with the goal of creating permanent and tamperproof records" (Treiblmaier, 2018, p.547). Thus BCT holds several important architectural properties.

One important architectural property of BCT is its decentralised structure. In the blockchain all the participants in the network have a copy of the same data, which is distributed across the peer-to-peer network. This property of BCT may be designed to allow greater accessibility to the dataset to everyone at any time and any place in the network (O'Dair and Beaven, 2017). However, there is a distinction between permissionless (public) and permissioned (private) blockchains. In public blockchains, the digital ledger is completely decentralised, and it can be accessed by any internet user. Hence, information about the transactions is broadly available to the network participants in a public setting (O'Leary, 2017). However, in a business setting, such information may provide competitors or other institution with the potential for business intelligence. As a solution, private blockchains can be implemented. In permissioned blockchains, only a preselected and limited number of participants are authorised to use the ledger. The entries in a fully private blockchain are monitored by a central authority (Siba and Prakash, 2016), which can decide to accept new members into the network and determine the level of access provided to members (Kewell et al., 2017).

Another important architectural property of BCT is the cryptography system, which promises immutability of data and further enables the tracking of chains of data and transactions over time (Ølnes et al., 2017; Nowiński and Kozma, 2017). From a technical perspective, it consists of two functions: keying and hashing. Keying works by using two different but related keys, either of which can encrypt or decrypt a message or transaction. If one key encrypts the message, only the other key can decrypt it (Brandon, 2016). Hashing allows blocks to be chained together in an immutable sequence (Haber and Stornetta, 1990). The header of each block contains a hash value reflecting the contents of the previous block, which itself includes a hash value derived from its predecessor, and so forth, all the way back to the first block in the chain (Yermack, 2017). Thus, new information cannot be forged retroactively by changing a prior entry in the blockchain because it would cause changes in the sequences of all subsequent entries (Biswas et al., 2017).

Yet another important architectural property of $\mathrm{BCT}$ is the consensus mechanism, through which quality and integrity in the blockchain can be provided. The consensus mechanism confirms that transactions are coded into blocks according to the cryptographic rules and enforces the time sequence placing of blocks on the chain (Brandon, 2016). This typical peerto-peer architecture contributes to the security as well as the immutability of the transactions which are recorded in the blockchain. Furthermore, the distributed consensus protocols can have several forms, such as majority voting, priority voting or having a minimal number of votes, to ensure the data integrity of the transactions (Ølnes et al., 2017). 
In some versions of BCT, the smart contract is added as an extra important architectural property. The smart contract is a computer program that can autonomously verify and execute the terms of contracts (Szabo, 1997). Thus, with this property, the blockchain has the ability to allow self-enforcement of contracts. All the various promises in the contract can be authenticated by the BCT, validating that each party has the ability to perform the tasks it is responsible for.

\subsection{Blockchain in SCM}

For SCM, the blockchain is positioned as a digital innovation, an emergent enabling technology (Buer et al., 2019). SCM is defined as the systemic, strategic coordination of traditional business functions and the tactics across these functions within a particular company and across businesses within the supply chain, for the purposes of improving the long-term performance of the individual companies and the supply chain as a whole (Mentzer et al., 2001). Through the above-mentioned architectural properties, the blockchain then provides unique technological qualities, such as immutability, automaticity, pseudonymity and nonrepudiability (irreversibility), which in turn may result in unparalleled reliability, transparency and efficiency in the supply chain (Treiblmaier, 2018).

Kshetri (2018) explores how the blockchain is likely to affect key SCM and performance objectives, such as cost, quality, speed, dependability, risk reduction, sustainability and flexibility. Based on analysis of secondary case data, it is concluded that the relation between blockchains and increased transparency and accountability is likely to be strong. It is further conjectured that the new technology may potentially affect all the explored objectives.

Petersen et al. (2017) perform one of the first mapping studies in the field and explore the stance of industry professionals towards blockchains. They identify 49 different applications of the blockchain, which may be grouped into three main clusters: product tracking, product tracing and supply chain finance. It is found that although most managers realise the potential impact of the new technology, the rather conservative logistics companies seem hesitant to adopt and invest in blockchain applications due to unclear performance benefits and employee effects.

Treiblmaier (2018) presents an agenda for the applicability and subsequent adoption of BCT in SCM. Based on the theoretical premises for SCM (Halldórsson et al., 2015), Treiblmaier's framework provides a good theoretical starting point for understanding the implications of blockchains in aiding SCM, though his propositions do not yet show the organisational workrelated managerial constraints and benefits of the BCT properties, which may affect its applicability. As the study of Petersen et al. (2017) shows, there is a distinct difference in terms of different managerial levels and professional backgrounds in how the benefits and effects of $\mathrm{BCT}$ are perceived. It is important to account for these managerial effects in order to have a better understanding of the technology-management-performance relationship (Hald and Mouritsen, 2013).

\subsection{Organisational technologies and supply chain performance}

Organisational technologies can have potentially enabling or constraining effects on organisation. This theory, presented by Adler and Borys (1996), proposes a conceptualisation of workflow formalisation which helps reconcile the contrasting assessments of bureaucracy as enabling employees to perform their tasks more effectively or as constraining and alienating to their work and performance.

The theory further defines organisational technology as an instance of formalisation which enables managerial intervention in organisational processes and workflow. Depending on its design, organisational technology may lead to both enabling and constraining effects. Thus, 
Adler and Borys (1996) predict that any organisational technology creates the possibility for both enabling and coercive bureaucracy.

From an SCM perspective, the blockchain may be understood as an organisational technology which spans multiple organisations and work processes and which helps supply chain managers intervene and manage the supply chain. However, its design affects supply chain actors' work and commitment and modifies the ability to manage the supply chain and reach desired levels of supply chain performance. Thus, embedding BCT in the supply chain may produce possibilities for both enabling and constraining formalisation.

Based on these considerations, a central question, then, is whether and how the blockchain understood as an organisational technology will be supportive of the ability to manage the supply chain and to enhance supply chain performance. The purpose of the present research is, therefore, to understand the enabling and constraining roles of BCT in managerial work practices, and to further conceptualise the technology-performance relationship for SCM. With this ambition in mind, the following research question is formulated:

\section{- How does the blockchain enable and constrain SCM and supply chain performance?}

\subsection{The enabling and constraining effects of BCT on supply chain performance}

Our research strategy follows Hald and Mouritsen (2013), which applies Adler and Borys (1996) to explore the enabling and constraining effects of enterprise resource planning systems in operations management. We look for evidence in the literature regarding how the blockchain as an organisational technology is imbued with a set of powerful identities, each with the potential to either enable or constrain different dimensions of SCM and supply chain performance. The analysis, therefore, not only observes enabling effects, but also simultaneously looks for the potential constraining/coercive effects which may potentially emerge from the same architectural properties or BCT design. Thus, the analyses acknowledge that enabling and constraining effects may go hand in hand, but also that they may be difficult to capture, as they may be dislocated across complex organisational structures such as a supply chain system (De Leeuw et al., 2013).

Specifically, Figure 1 shows the theoretical model. The theoretical model projects that when the blockchain is understood as an organisational technology, it can lead to both enabling formalisation and coercive formalisation in the supply chain. Whether it results in an enabling or coercive formalisation is affected by its design. Thus, the theoretical model projects that the same architectural property of the blockchain or combination of properties (e.g., decentralised structure, cryptographic mechanism, consensus mechanism, smart contract) can result in either enabling formalisation or coercive formalisation, depending on how these properties are taken into account in the supply chain.

When the blockchain is enabling, it is designed with usability and an upgrading rationale, it supports and enhances supply chain capabilities and leverages supply chain skills and intelligence (Adler and Borys, 1996). Thus, supply chain actors are seen as sources of skills and intelligence to be supported. When the blockchain enables, it moves organisational processes in new and desirable directions and it will immediately or over time increase supply chain performance.

When the blockchain is constraining, it is designed with a fool-proofing and deskilling rationale, it substitutes commitment with procedures, and it coerces effort and compliance from supply chain actors (Adler and Borys, 1996). Thus, supply chain actors are seen as sources of problems to be eliminated. When the blockchain constrains, it hinders the supply chain, its processes and its actors in performing to their potential and it decreases supply chain 
performance. Supply chain performance is understood as the efficiency and effectiveness of supply chain processes and relationships (Maestrini et al., 2017), and it may be operationalised as a set of supply chain performance dimensions or objectives (Kshetri, 2018).

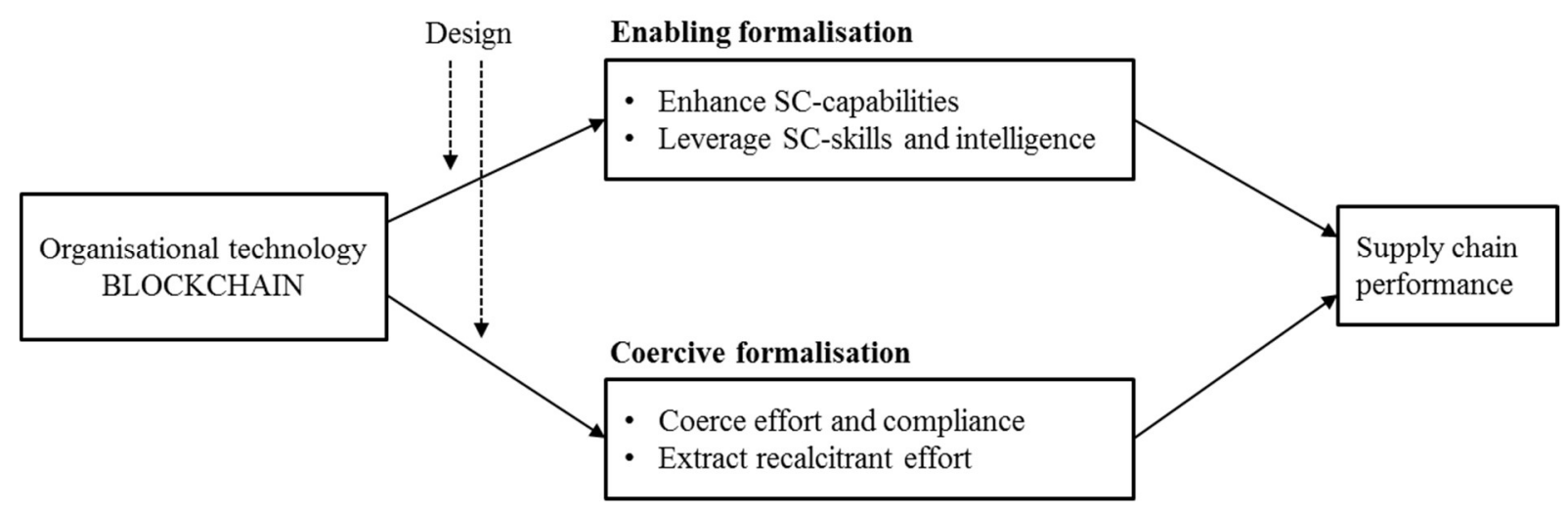

Figure 1: Theoretical model developed on the basis of Adler and Borys (1996) and Hald and Mouritsen (2013)

\section{METHODOLOGY}

The approach used in this research is based on a structured literature review which was performed in September 2018. The review followed a three-step approach (Tranfield et al., 2003). In the first step, an advanced search was designed and executed using Business Source Complete as a search engine. In the search, we looked for different keywords in the abstract, including 'blockchain', 'block-chain' and 'distributed ledger'. Since the keywords were considered to be synonyms, the terms were separated using the conjunction 'or'. This enabled the collection of a larger sample of relevant literature (Tranfield et al., 2003). This produced a sample of 2868 papers. Consistent with the research strategy, the sample was then narrowed to focus on scholarly peer-reviewed academic journals in English. This reduced the obtained sample to 257 papers. In order to identify relevant papers which had not yet appeared as academic publications on Business Source Complete, it was decided to supplement the sample with two additional searches. The databases Google Scholar and ResearchGate were used for these searches. As a result of these searches, ten additional papers of potential relevance were added to the sample.

In the second step and in order to identify papers which could help us synthesise a theory-driven understanding of how BCT may be taken into account to support or to constrain SCM and its performance, the 267 abstracts were screened. In this process, relevance was defined using two screening criteria: First, the study had to deal with blockchains as its main topic. Second, the study had to discuss managerial- and performance-related implications of using BCT in functions, organisations, supply chains or industries. To increase reliability, the screening process was performed by all involved researchers individually and then subsequently compared and discussed until agreement was reached on which papers to include and which papers to exclude. Using these criteria, the sample was reduced to 48 .

In relation to descriptive information regarding the sources included in the final sample, all the included material was peer-reviewed academic material. Of the works included, $90 \%$ had appeared in academic journals, $4 \%$ as conference papers, $4 \%$ as book chapters and $2 \%$ as working papers. In addition, $49 \%$ of the academic journal papers were listed and ranked on the ABS list. In relation to topics and research communities, $25 \%$ of the works had appeared in management information systems and knowledge management outlets, $21 \%$ in general 
management and strategy, $17 \%$ in finance and accounting, $15 \%$ in production and operations management and $10 \%$ in outlets concerned with legal issues. The remaining $12 \%$ appeared in outlets concerned with publishing sector management, sociology, economics and entrepreneurship and sustainability. Finally, $66 \%$ of the papers included a specific focus on the relation between blockchains and SCM.

In the final step, a coding process was performed to identify the enabling and constraining effects of BCT on SCM. The coding process was developed based on Adler and Borys (1996) and Miles and Huberman (1994). First, each of the identified publications was coded individually. Specifically, words or phrases were sought indicating how the blockchain could/would act and reach its projected effects, such as 'the blockchain facilitates', 'the blockchain will revolution', 'transformative potential' and 'disruptive potential'. To increase reliability, the identified effects were then listed in a comprehensive table and compared and discussed among the involved researchers until a consensus emerged. As the final step, the researchers looked for patterns across the sample that would help deduce different blockchain identities. For that purpose and following Ashforth and Mael (1989), blockchain identity was defined as the idiosyncratic characteristics related to the abilities and effects of the blockchain.

\section{THE DIFFERENT BLOCKCHAIN IDENTITIES}

The outcome of our coding produced four enabling and three constraining blockchain identities in relation to how the blockchain was understood to implicate SCM and supply chain performance. Following Morgan (2006), the identities were formulated as metaphors, enabling the researchers to better explore and highlight the complexities of the relationship between BCT and SCM. Table A presents the outcome of the structured review. The different identities and propositions that arose during the analysis will now be presented.

$<<$ Insert Table A approximately here $>>$

\subsection{The enabling blockchain}

The analysis identified four aspects of the blockchain which potentially enable SCM, each of which portrays the blockchain with a particular identity: information lighthouse, exploitation technology, exploration technology and relationship-building technology. While the information lighthouse identity focuses narrowly on the relation between BCT and data quality, the remaining identities focus on the relation between BCT and the ability to manage existing or new supply chain processes, or to forge stronger or new supply chain relationships.

\subsubsection{The blockchain as an information lighthouse}

Because the supply chain in its nature is a distributed network of actors and organisational entities, it includes activities and transactions which are dislocated across time and space. The ability to enhance supply chain transparency is therefore a fundamental ambition of SCM, and one directly related to the ability to improve supply chain performance (e.g., Prajogo and Olhager, 2012).

The ability to enable SCM rests on a set of data qualities enabled by BCT. First and following from the decentralised structure of the blockchain, one central enabling aspect of BCT is its potential to make data available across a distributed network of peer-to-peer nodes (e.g., Koonce, 2016; Nowiński and Kozma, 2017). Second, the cryptography system promises immutability of data and enables the tracking of chains of data and transactions over time 
(Biswas et al., 2017; Nowiński and Kozma, 2017). Third, the consensus mechanism enables data consistency across the distributed peer-to-peer network of blockchain nodes (Siba and Prakash, 2016):

- Proposition 1a: Use of BCT in a supply chain enables data availability.

- Proposition 1b: Use of BCT in a supply chain enables data immutability.

- Proposition 1c: Use of BCT in a supply chain enables data consistency.

Based on these considerations and on the analysis of the literature on BCT, two aspects of transparency which may potentially be affected by the blockchain are identified: supply chain visibility and supply chain traceability. When understood as an enabler of supply chain visibility, the blockchain enhances the ability of the individual actor or node to see and know more about all activities and processes which take place in the supply network, and which are not immediately visible to the actors (e.g., Eljazzar, 2018; White, 2017). This is thus a potential improvement of a managerial ability, which enables firms to better see across tiers in the supply chain, both upstream and downstream (O'Leary, 2017). The blockchain may therefore also be understood to play an important role in integrating decentralised resources in industries which are characterised as scattered, small, disorderly and weak, thereby improving system efficiency (Leng et al., 2018). In line with other definitions of supply chain visibility, the blockchain can thus be considered to be an organisational technology which supports a process that captures and transfers information 'more' accurately, timely and completely among business partners in a supply chain (e.g., Arcos, 2018; Petersen et al., 2017).

When understood as a technology which enhances transparency, the blockchain is seen as enabling its members to trace transaction histories (Adams et al., 2017b; Francisco and Swanson; 2018). In relation to products, the blockchain will thus enable its users to attach an indelible record of a product's precise history (Koonce, 2016). This may be related to points of origin of components and products consumed by the blockchain members or by its end customers. Thus, BCT enables the disclosure of information and will increase knowledge about the origin of products (Nowiński and Kozma, 2017), which in turn will enable better decisions regarding issues such as sustainability (Ølnes et al., 2017; Nowiński and Kozma, 2017) and supply safety or forgery (Nowiński and Kozma, 2017; Subramanian, 2018).

Traceability, however, may also be understood to work on other dimensions, such as that of ownership of assets (Yermack, 2017). Because an audit trail may be available on every historical action and activity (Ølnes et al., 2017), the potential to make audits of all sorts may be understood to be improved. This potential can be seen as a strengthening of the overall ability to control the supply chain and its activities (Francisco and Swanson; 2018). It can also be seen as an issue of fairness and, subsequently, trust. When everything is stored in supply chain memory and can be retrieved by all actors at any time, knowledge of past events can no longer be convincingly contested. Past transactions become irrefutable, and this enables initiatives to reduce corruption and fraud (Kshetri, 2017) and increased trust in data (Kim and Justl, 2018). The above arguments thus suggest the following propositions:

- Proposition 2: Use of BCT in a supply chain enables increased supply chain visibility.

- Proposition 3: Use of BCT in a supply chain enables increased supply chain traceability.

\subsubsection{The blockchain as an exploitation technology}

Following March's (1991) seminal distinction between exploitation and exploration, the blockchain can be understood as a technology leading to improved managerial ability to exploit existing supply chain resources and competencies. Managerial focus is on alignment, systematic improvement and refinement of existing capabilities (March, 1991). The literature 
supports several ways in which the blockchain can be understood as a technology which enables exploitation.

First, BCT is seen as a technology which reduces the potential for errors (Brandon, 2016; Ølnes et al., 2017). Following Propositions $1 \mathrm{~b}$ and 1c, the blockchain is understood to secure data consistency and data immutability. That is, in a blockchain, errors in the form of mistakenly recorded data and other types of inconsistencies can be assumed to be minimised or even completely eliminated. When errors occur and are corrected, updates will take place automatically in every place at once, rather than the current situation, which requires the contacting of each individual note in the network (O'Dair and Beaven, 2017). When fewer errors occur and/or when errors are easily detected and corrected throughout the supply chain, there is a reduction in supply chain risk, understood as the potential malicious consequences of data inconsistencies and errors to the supply chain. The risk of attacks from hackers to a single database is also avoided because of the decentralised structure of the blockchain (Ølnes et al., 2017). The above arguments thus suggest the following propositions:

- Proposition 4a: Use of BCT in a supply chain enables reduction of errors.

- Proposition 4b: Use of BCT in a supply chain enables reduction of attacks.

Second, and following proposition 2, BCT can be understood to enable better coordination. With improved visibility, each participant in the supply chain will be able to see the progress of goods as they move through the supply chain. This will enable each participant to understand where particular goods or containers are in transit. Participants can also determine the status of customs documents, view bills of lading and view other types of data in real time ( $\mathrm{O}^{\prime}$ Leary, 2017). The argument is that this will support coordination and planning in and around the flow of goods and documents in the supply chain, which in turn may help increase efficiency (Nowiński and Kozma, 2017; Voshmgir, 2017; Koonce, 2016). Because of the potential that every node can see everything, another effect of complete supply chain visibility may be the avoidance of duplication in similar or identical tasks performed in different locations in the supply chain (O'Leary, 2017). However, because of the potential to limit data availability in private blockchain designs, the suggested enabling effects related to supply chain visibility will be moderated by blockchain membership and by data availability rules controlled by a central authority. The above arguments thus suggest the following proposition:

- Proposition 5: Use of BCT in a supply chain enables enhanced supply chain coordination.

Third, blockchains and the smart contract may be understood to reduce transaction costs of reaching and enforcing supply chain agreements (Appelbaum and Smith, 2018). This enables the formalisation and enforcement of agreements throughout the supply chain. That is, it governs agreements in relationships between firms as well as between all other types of actors in the supply chain and the assets they possess (Casado-Vara et al., 2018). This is achieved by standardising transaction rules (Szabo, 1997). The agreement, understood as a transaction rule - set, in the smart contract defines the conditions, rights and obligations to which supply chain actors are contractually bound. The opportunity to improve supply chain efficiency can be further supported by automation in the enforcement of the contract (Giancaspro, 2017; Tapscott and Tapscott, 2017). As soon as the parties have come to an agreement and met the conditions of the agreement, the rights and obligations established in the smart contract can be automatically executed by the blockchain (Coyne and McMickle, 2017; Szabo, 1997). One example is automated payment processing depending on the status of a shipment (Petersen et al., 2017). This can be summarised in:

- Proposition 6: Use of BCT in a supply chain enhances contract management and supply chain governance. 
Fourth, a central promise of BCT is its potential to eliminate intermediaries and thereby create market efficiency (Koonce, 2016). One central type of intermediary which may potentially be eliminated is the central authority whose main function is to validate transactions. With BCT, parties to a transaction can store and exchange value without the need for a traditional intermediary. Representations of value will no longer be confined to a local space but will instead be part of the distributed ledger available to all relevant parties with access (Tapscott and Tapscott, 2017). Thus, the blockchain will potentially eliminate the need for a central authority to validate transactions, thus realising many supply chain efficiencies. Transaction costs due to contract enforcement, such as following a sale, can be eliminated when the network validates the transaction (Subramanian, 2018). This allows for considerable savings on costs associated with enforcement, such as labour expenses, legal fees, court costs and tax advisors. Administrative functions acting at the boundary between firms in the supply chain and with the purpose of calling off orders, checking delivery times, handling invoicing and payments may also be severely reduced or entirely eliminated due to the increased visibility of transactions and the potential to avoid non-value-adding double functions (Nowiński and Kozma, 2017; Subramanian, 2018). This in turn will not only enhance supply chain efficiency directly but will reduce system complexity in general (Underwood, 2016; Voshmgir, 2017; Nowiński and Kozma, 2017; Seidel, 2018; Adams et al., 2017b; Bridgers, 2017), which may also shorten administrative lead times and improve flexibility and responsiveness (Underwood, 2016; Nowiński and Kozma, 2017; Brandon, 2016). This can be summarised in:

\section{- Proposition 7: Use of BCT in a supply chain enables reduction in structural complexity.}

\subsubsection{The blockchain as an exploration technology}

Following March's (1991) distinction, the blockchain can also be understood as a technology leading to improved managerial ability to explore new supply chain routines and approaches. Managerial focus is on radical process improvement, flexibility, search and experimentation (March, 1991). The literature supports several ways in which the blockchain can be understood as a technology which enables exploration.

$\mathrm{BCT}$ is in some part seen as a technology with the potential to create fresh opportunities for value creation and capture (Maull et al., 2017), and as an opportunity for constructing entirely new supply chain structures and forms of economic and social governance (Kewell et al., 2017). One example is the creation of new electronic markets (e-markets) where buyers and supplier can be matched very easily and with low cost (Subramanian, 2018). Specifically, these new emarkets will enable both reach and immediacy (Subramanian and Overby, 2017), and this will facilitate the sharing of resources and the combining of supply chain processes in new and innovative ways. BCT may also enable innovation in manufacturing and help transform traditional standalone manufacturing into decentralised or open manufacturing, which may further enhance social and environmental sustainability (Li et al., 2018).

The blockchain can also be seen as an opportunity to rethink important decisions concerning, for instance, sustainability and the sourcing of components (Kewell et al., 2017). Following proposition 3, BCT can be understood to provide radical new knowledge to understand the origin of products. This knowledge in turn may inspire firms and entire supply chains to shift sourcing patterns away from unsuitable sources to new and much more sustainable ones. This may generate opportunities for new value propositions to the market, which may be possible because knowledge is made sticky and attaches to the individual components flowing through the supply chain. BCT adoption may even be thought of as potentially enabling a circular economy, closed-loop supply chains and reverse logistics (Saberi et al., 2018). The above arguments thus suggest the following propositions: 
- Proposition 8: Use of BCT in a supply chain enables radical supply chain restructuring and innovations.

- Proposition 9: Use of BCT in a supply chain enables supply chain sustainability innovations.

\subsubsection{The blockchain as a relationship-building technology}

In the literature, BCT is seen as an opportunity to cooperatively share value across boundaries (Manski, 2017) and as a mechanism for improving trust in transactions (Kshetri, 2017). Additionally, improved transparency will enable supply chain actors to know more about the business partners who are integrated into the blockchain. This will enable them to collaborate in real time across wide space, in different countries and even on different continents (Anderson, 2018). However, the specific blockchain design or configuration of the blockchain must be aligned with the relationships between the agents involved in the transactions ( $\mathrm{O}^{\prime}$ Leary, 2017). These and other proposed effects and considerations highlight the blockchain as a technology which has the potential to influence the ability to gain relational rents (Dyer and Singh, 1998) from supply chain relationships.

Following Proposition 2, the blockchain increases supply chain visibility. Therefore, it can be seen as a technology which enables firms in supply chain relationships to enhance collaboration (Anderson, 2018). Involved firms can now better combine, exchange and invest in idiosyncratic assets, knowledge and resources/capabilities because they are now better known to the partners embedded in the blockchain (Kshetri, 2017). This will facilitate higher levels of sharing of knowledge, resources and services in manufacturing ecosystems and supply networks (Eljazzar et al., 2018; Li et al., 2018). Additionally, following the discussion above as well as Proposition 6 on supply chain governance, the blockchain is also proposed as a technology which enables effective governance mechanisms to increase trust and lower transaction costs. In combination and building on the relational view by Dyer and Singh (1998), the following proposition is suggested:

- Proposition 10: Use of BCT in a supply chain enhances the potential to gain relational rents from supply chain partnerships.

\subsection{The constraining blockchain}

When the blockchain constrains, it hinders the supply chain in reaching its full potential and reduces supply chain performance. It hinders the supply chain in performing to its full potential either by blocking it from more beneficial territories, by erasing parts of its competitiveness or by introducing new uncertainties and risks. The analysis identified three aspects of the blockchain which constrain SCM; each portrays the blockchain with a particular identity.

\subsubsection{The blockchain as a domination technology}

Too much supply chain transparency may create challenges because it can compromise data privacy issues (Bridgers, 2017; Underwood, 2016) and can be mobilised as a source of power and surveillance. When every action, activity and transaction is immediately visible and further stored permanently in technology memory, this might produce the possibility for a powerful actor either inside (e.g., powerful buyer) or outside (e.g., government or other authority) the supply chain to monitor and to dominate by surveillance or request supply chain actors to deliver even more transparency (Adams et al., 2017b). In this view, the blockchain understood as a Panopticon creates a consciousness of permanent visibility as a form of power and a potential for domination (Foucault, 2012). Because of the decentralised structure, cryptography system and consensus mechanism, removing data from the blockchain is virtually impossible, since it will require that all or in some cases a majority of all users of the blockchain 
simultaneously agree to remove the data (Bridgers, 2017). There is also an issue with regard to who designs and owns the specific blockchain (O'Dair and Beaven, 2017). Powerful corporations could set up private, permissioned blockchains and invite other firms to participate in a space where tie-in situations and monopolies would emerge over time. In this light, BCT will lead to the strengthening of hierarchies and the centralisation of power (Manski, 2017).

Another potential adverse effect of the ability of blockchains to produce visibility and traceability may be increased supply chain segregation. The blockchain might force firms to think about which types of information and knowledge to protect from transparency (Kim and Justl, 2018). It is most likely that firms will be interested in maintaining some sort of information asymmetry to keep competitive advantages and to further reduce the risk of information leakages (Coyne and McMickle 2017; Yermack, 2017).

Additionally, some customers and consumers may begin to shift to suppliers who provide more complete information about the history of their products, and this can lead to radical shifts in the marketplace (Koonce, 2016). Dominant firms may want to invite into their close blockchain communities only other firms they already consider to be core supply chain partners. Even when inside, dominant firms may act as central authorities restricting access to information which might have been useful for less dominant members of the blockchain and for the supply chain as a whole to coordinate activities. The above arguments thus suggest the following propositions:

- Proposition 11a: Use of BCT in a supply chain leads to increased surveillance and the enforcement of power.

- Proposition 11b: Use of BCT in a supply chain leads to supply chain segregation.

\subsubsection{The blockchain as a straitjacket}

There might be adverse effects from embedding the blockchain in supply chains to reflect current activities and current supply chain relationships. In this light, the blockchain can be seen as a transaction-specific investment and a straitjacket which may keep current operations in place, although the market and competitive situation surrounding the supply chain is dynamic. In this view, some research has discussed the inflexibility of smart contracts (Kewell et al., 2017; Voshmgir, 2017). The danger is that the smart contract performs no matter what, and this raises the question about who writes it (Kewell et al., 2017). Another potentially cohesive effect of smart contracts is that they are impossible to modify in the event of any changes in needs which were not considered when stipulating the contract (Sklaroff, 2017). Moreover, smart contracts may be difficult to adapt to current legal frameworks regulating contracts across jurisdictions (Giancaspro, 2017). Other research points to the scalability problem (Saberi et al., 2018). Computer power and the time and memory required to confirm transactions in a blockchain is increasing (Manski, 2017), and current computer infrastructures may not be able to keep pace with the growth of blockchain (Giancaspro, 2017). It is further argued that distributed solutions such as blockchains are much more inefficient than traditional centralised database solutions because they are more difficult to scale up to higher capacity and cannot easily be changed, resulting in less flexibility (Underwood 2016; Ølnes, 2017). This leads to:

\section{- Proposition 12: Use of BCT in a supply chain reduces supply chain adaptability.}

\subsubsection{The blockchain as a deskiller}

Because organisational technology can be designed with the intention of automating and eliminating work, it will potentially also have deskilling implications for workers (Orlikowski, 1992) and organisations. Based on the analysis of the literature, the blockchain may be understood as a technology which has the power to erase parts of supply chain competencies 
(Manski, 2017). Due to the potential for automation following the design of BCT, many middleand lower-income workers in the areas of accounting, verification, banking and other disciplines may lose their livelihoods. Unique but intangible knowledge embedded in the supply chain or in boundary-spanning functions may be lost or reduced because of automation of work procedures and elimination of transaction intermediaries. In addition, the increased potential for control enabled by the permanent and immutable storage of data might cause workers' autonomy to be restricted with single job tasks being exactly prescribed, measured and evaluated, and existing qualifications and skills may lose value (Treiblmaier and Umlauff, forthcoming). There may also be a challenge with organisational or work commitment as functions are completely or partly automated and replaced with procedures (Adler and Borys, 1996). This leads to the final proposition:

- Proposition 13: Use of BCT in a supply chain reduces worker skills and supply chain competencies.

\section{DISCUSSION}

The blockchain as an information lighthouse and specifically its ability to enable increased supply chain traceability emerged in the analysis as the most dominant outcome of the technology (see Appendix A). In addition, the blockchain understood as an exploitation device figured strongly in the analysis, and here BCT-enabled enhanced contract management and supply chain governance was found to be especially eminent. Less prominent were the blockchain's ability to work as an innovation engine and relationship-building technology. This shows that there is a tendency in the literature to see the blockchain as an opportunity to exploit existing supply chain resources and competencies, and, based on the analysis of the literature sample, it seems that managerial focus is on alignment, systematic improvement and refinement of existing capabilities. This finding relates well to the largely transformative potential which is expected of the technology (Iansiti and Lakhani, 2017). In relation to the eminent traceability focus, we propose that this stems from the key/core innovation of BCT as providing data immutability, something not provided in other supply chain technologies (Mougayar, 2016).

The analysis also shows how blockchain enables and constrains multiple dimensions of supply chain performance. Specifically, it demonstrates how cost, resilience, responsiveness, adaptability, sustainability and innovation are all supply chain performance objectives potentially affected when the blockchain is embedded in the supply chan. These findings complement Kshetri (2018) in identifying the same potential performance outcomes of embedding BCT in a supply chain. However, the findings also extend previous research, as they show how the same architectural properties of BCT can lead to both enhancements and reductions in supply chain performance. In concert, the analysis shows that the blockchain is a Janus-faced organisational technology which can take on a complex portfolio of different powerful identities, depending on its specific design (Adler and Borys, 1996). This supports Manski (2017) when arguing that BCT has potential in both leading towards and away from a technological commonwealth.

Another central contribution of this study is to show how future research on the use of BCT in supply chains can heighten its theoretical relevance and foundation. Specifically, the study demonstrates how the organisational theory suggested by Adler and Borys (1996) holds potential for future studies seeking to understand the managerial implications of adopting BCT in a supply chain. In relation to previous academic research in the area, the present study adds to Kshetri (2018) and Petersen et al. (2017) by addressing not only the final outcome of the use of BCT on dimensions of supply chain performance, but also the complex path which creates this outcome. The presented research further complements the theoretical agenda for the 
applicability and subsequent adoption of BCT in SCM presented by Treiblmaier (2018). This is done by furthering the blockchain as an organisational technology and exploring the organisational work-related managerial benefits or constraints which may affect its applicability.

Like most studies, this research contains some limitations. A limitation of the present study is that findings are based on a literature synthesis and theoretical conceptualisation. The deduced blockchain identities are the result of narrative coding. An alternative search strategy and/or alternative coding would likely have resulted in a different set of enabling and constraining effects. There is also some concern that some of the deduced effect categories or 'representations' can be understood as oversimplifications. This is an inherent challenge when using a conceptual approach to construct an overview and direction of a set of intervened and complex phenomena (Miles and Huberman, 1994).

\section{CONCLUSION}

The purpose of this study was to explore how the blockchain enables and constrains SCM and supply chain performance. The study highlights how BCT should be understood to have a multifaceted and diverse impact on SCM and supply chain performance. Specifically, the study develops a set of propositions, each of which highlights a different path of how these impacts might manifest.

The analysis identified four different blockchain identities which enable SCM and improve supply chain performance: information lighthouse, exploitation technology, exploration technology and relationship-building technology. However, the analysis also identified three different blockchain identities which constrain SCM and reduce supply chain performance: domination technology, straitjacket and deskiller.

Practitioners can benefit from the study results by noting the importance of the identified enabling and constraining roles of the blockchain. This knowledge has the potential to serve as a set of guidelines, through which supply chain managers should be aware of the potential for simultaneous parallel enabling and constraining effects of embedding BCT in a supply chain. Ideally, supply chain managers should seek to enhance the enabling powers and minimise the constraining powers of the blockchain.

Future research should test the developed propositions to provide a deeper understanding of each of the identified enabling and constraining roles and their implications for SCM. In general, more research is suggested focussing on BCT as an opportunity to explore and innovate and as a relationship-building technology. More studies adopting organisational theory to explore the simultaneous and complex chain of both enabling and constraining implications of BCT in supply chains are also strongly recommended.

\section{ACKNOWLEDGEMENTS}

We would like to thank student Lorenzo Russo for assisting us with the research. We would also like to thank the two anonymous reviewers and the guest editors for providing invaluable feedback and comments to this paper. 


\section{REFERENCES}

Adams, R.J., Smart, P. and Huff, A.S. (2017a), "Shades of grey: guidelines for working with the grey literature in systematic reviews for management and organizational studies", International Journal of Management Reviews, Vol.19 No.4, pp.432-454.

Adams, R., Parry, G., Godsiff, P., and Ward, P. (2017b), "The future of money and further applications of the blockchain", Strategic Change, Vol.26 No.5, pp.417-422.

Adler, P.S. and Borys, B. (1996), "Two types of bureaucracy: enabling and coercive", Administrative Science Quarterly, Vol.41, pp.61-89.

Anderson D. (2018), "How blockchain will revolutionize the video games industry", Intellectual Property \& Technology Law Journal, Vol.30 No.7, pp.17-19.

Appelbaum D. and Smith S. (2018), "Blockchain basics and hands-on guidance: taking the next step toward implementation and adoption", CPA Journal, Vol.88 No.6, pp.28-37.

Apte S. and Petrovsky N. (2016), "Will blockchain technology revolutionize excipient supply chain management?". Journal of Excipients and Food Chemicals, Vol.7 No.3, pp.76-78.

Arcos, L.C. (2018) "The blockchain technology on the music industry", Brazilian Journal of Operations \& Production Management, Vol.15 No.3, pp.439-443.

Ashforth, B.E. and Mael, F. (1989). "Social identity theory and the organization", Academy of management review, Vol.14 No.1, pp.20-39.

Biswas K, Muthukkumarasamy V. and Tan WL. (2017), "Blockchain based wine supply chain traceability system", Future Technologies Conference, December.

Bocek, T., Rodrigues, B.B., Strasser, T. and Stiller, B. (2017), "Blockchains everywhere-a usecase of blockchains in the pharma supply-chain", In Integrated Network and Service Management, 2017 IFIP/IEEE Symposium on, IEEE, pp.772-777.

Brandon, D. (2016), "The blockchain: the future of business information systems?", International Journal of The Academic Business World, Vol.10 No.2, pp.33-40.

Bridgers, A. (2017), "Will workplaces be going off the rails on the blockchain?", Journal of Internet Law, Vol.20 No.11, pp.3-6.

Buer, T., Hassis, H-D, Kinra, A. and Kotzab H. (2019), "An overview to contemporary maritime logistics and supply chain management decision areas", in Panayides, P. (ed.), Routledge Handbook of Maritime Management, Routledge.

Burkett, M. and Johnson, J. (2016), "Supply chain 2025: planning today for tomorrow". Available at: https://www.gartner.com/doc/3367817/supply-chain--planning-today (accessed: 4.December 2018).

Casado-Vara, R., Prieto, J., la Prieta, F.D. and Corchado, J.M. (2018), "How blockchain improves the supply chain: case study alimentary supply chain", Procedia Computer Science, Vol.134, pp.393-398.

Clauson K.A, Breeden E.A, Davidson C. and Mackey T.K. (2018), "Leveraging blockchain technology to enhance supply chain management in healthcare: an exploration of challenges and opportunities in the health supply chain", Blockchain in Healthcare Today, pp.1-12.

Coyne, A. (2017), "Food giants Nestlè and Unilever link up with IBM on blockchain project", Aroq-Just-Food.Com (Global News), p.13.

Coyne J.G. and McMickle P.L. (2017), "Can blockchains serve an accounting purpose?" Journal of Emerging Technologies in Accounting, Vol.14 No.2, pp.101-111.

Dai J. and Vasarhelyi MA. (2017),"Toward blockchain-based accounting and assurance", Journal of Information Systems, Vol.31 No.3, pp.5-21.

Dai J, Wang Y. and Vasarhelyi MA. (2017), "Blockchain: an emerging solution for fraud prevention", CPA Journal, Vol.87 No.6, pp.12-14. 
De Leeuw, S., Grotenhuis, R. and van Goor, A.R. (2013), "Assessing complexity of supply chains: evidence from wholesalers", International Journal of Operations \& Production Management, Vol.33 No.8, pp.960-980.

Dyble, J. (2018), "Global blockchain in supply chain market to reach $\$ 424 \mathrm{mn}$ by 2023", available at: https://www.supplychaindigital.com/technology/global-blockchain-supplychain-market-reach-424mn-2023/(accessed 15.November 2018)

Dyer, J.H. and Singh, H. (1998), "The relational view: cooperative strategy and sources of interorganizational competitive advantage", Academy of management review, Vol.23 No.4, pp.660-679.

Eljazzar, M.M., Amr, M.A., Kassem, S.S., and Ezzat, M. (2018). Merging supply chain and blockchain technologies, The international maritime transport and logistics conference (Marlog 7): Innovation in ports "The gateway to the future" 18-20.March, pp.1-7.

Francisco K. and Swanson D. (2018), "The supply chain has no clothes: technology adoption of blockchain for supply chain transparency”, Logistics, Vol.2 No.1, pp.1-13.

Filipova N. (2018), "Blockchain - An opportunity for developing new business models", Business Management, Vol.2, pp.75-92.

Foucault, M. (2012), “Discipline and punish: The birth of the prison”, Vintage.

Giancaspro M. (2017), "Is a 'smart contract' really a smart idea? Insights from a legal perspective", Computer Law and Security Review, Vol.33 No.6, pp.825-835.

Haber, S. and Stornetta, W.S. (1990), "How to time-stamp a digital document", In Conference on the Theory and Application of Cryptography, Springer, Berlin, Heidelberg, pp.437-455.

Hald, K.S. and Mouritsen, J. (2013), "Enterprise resource planning, operations and management", International Journal of Operations \& Production Management, Vol.33 No.8, pp.1075-1104.

Halldórsson, A., Hsuan, J. and Kotzab, H. (2015), "Complementary theories to supply chain management revisited - From borrowing theories to theorizing", Supply Chain Management: An International Journal, Vol 20 No.6, pp.574-586.

Hawlitschek, F, Notheisen, B. and Teubner, T. (2018), "The limits of trust-free systems: a literature review on blockchain technology and trust in the sharing economy", Electronic Commerce Research \& Applications, Vol.29, pp.50-63.

Iansiti, M. and Lakhani, K.R. (2017), "The truth about blockchain”, Harvard Business Review, Vol.95 No.1, pp.118-127.

Kewell B, Adams R. and Parry G. (2017), “Blockchain for good?”, Strategic Change, Vol.26 No.5, pp.429-437.

Kim K. and Justl J.M. (2018), "Potential antitrust risks in the development and use of blockchain", Journal of Taxation \& Regulation of Financial Institutions, Vol.31 No.3, pp.516.

Kim H.M. and Laskowski M. (2018), "Toward an ontology-driven blockchain design for supply-chain provenance", Intelligent Systems in Accounting, Finance and Management, Vol.25 No.1, pp.18-27.

Koonce, L. (2016), "The wild, distributed world: get ready for radical infrastructure changes, from blockchains to the interplanetary file system to the internet of things", Intellectual Property \& Technology Law Journal, Vol.28 No.10, pp.3-5.

Kshetri N. (2017), "Will blockchain emerge as a tool to break the poverty chain in the Global South?", Third World Quarterly, Vol.38 No.8, pp.1710-1732.

Kshetri, N. (2018), "1 Blockchain's roles in meeting key supply chain management objectives”, International Journal of Information Management, Vol.39, pp.80-89. 
Lacity M.C. (2018), "Addressing key challenges to making enterprise blockchain applications a reality", MIS Quarterly Executive, Vol.17 No.3, pp.201-222.

Leng K, Bi Y, Jing L, Fu HC. and Van Nieuwenhuyse I. (2018), "Research on agricultural supply chain system with double chain architecture based on blockchain technology", Future Generation Computer Systems, pp.641-649.

Li Z, Wang W.M, Liu G, Liu L, He J. and Huang G.Q. (2018), “Toward open manufacturing”, Industrial Management \& Data Systems, Vol.118 No.1, pp.303-320.

Lyall, A., Mercier, P. and Gstettner, S. (2018) "The death of supply chain management", Harvard Business Review Digital Articles, pp. 2-4. Available at: https://hbr.org/2018/06/the-death-of-supply-chain-management/ (accessed: 22.November 2018).

Manski S. (2017), "Building the blockchain world: technological commonwealth or just more of the same?", Strategic Change, Vol.26 No.5, pp.511-522.

March, J.G. (1991), "Exploration and exploitation in organizational learning", Organization Science, Vol.2 No.1, pp.71-87.

Maestrini, V., Luzzini, D., Maccarrone, P. and Caniato, F. (2017), "Supply chain performance measurement systems: a systematic review and research agenda". International Journal of Production Economics, Vol.183, pp.299-315.

Maull R, Godsiff P, Mulligan C, Brown A. and Kewell B. (2017), "Distributed ledger technology: applications and implications", Strategic Change, Vol.26 No.5, pp.481-489.

Mentzer, J.T., DeWitt, W., Keebler, J.S., Min, S., Nix, N.W., Smith, C.D. and Zacharia, Z.G. (2001), "Defining supply chain management". Journal of Business logistics, Vol.22 No.2, pp.1-25.

Miles, M.B. and Huberman, A.M. (1994), Qualitative Data Analysis - An Expanded Sourcebook, Sage, London.

Morgan, G. (2006), Images of Organization, Sage: Toronto.

Mougayar, W. (2016). The Business Blockchain: Promise, Practice, and Application of the Next Internet Technology, Wiley:New Jersey.

Nair M. and Sutter D. (2018), "The blockchain and increasing cooperative efficacy", Independent Review, Vol.22 No.4, pp.529-550.

Nowiński, W. and Kozma, M. (2017), "How can blockchain technology disrupt the existing business models?", Entrepreneurial Business \& Economics Review, Vol.5 No.3, pp.173188.

O'Dair, M. and Beaven, Z. (2017), "The networked record industry: how blockchain technology could transform the record industry", Strategic Change, Vol.26 No.5, pp.471480.

O'Leary, D.E. (2017), “Configuring blockchain architectures for transaction information in blockchain consortiums: the case of accounting and supply chain systems", Intelligent Systems In Accounting, Finance \& Management, Vol.24 No.4, pp.138-147.

Orlikowski, W.J. (1992),"The duality of technology: rethinking the concept of technology in organizations", Organization science, Vol.3 No.3, pp.398-427.

Panetta, K. (2016), “Gartner's top 10 strategic technology trends for 2017”. Available at: http://www.gartner.com/smarterwithgartner/gartners-top-10-technology-trends-2017/ (accessed: 4.December 2018).

Panetta, K. (2017), "Top 10 mistakes in enterprise blockchain projects". Available at: http://www.gartner.com/smarterwithgartner/top-10-mistakes-in-enterprise-blockchainprojects/(accessed: 4.December 2018). 
Pedersen, A.Ø. (2018), "22 EU member states sign blockchain partnership", available at: https://shippingwatch.com/secure/carriers/article10659436.ece/ (accessed: 15.November 2018).

Petersen, M., Hackius, N. and von See, B. (2017), "Mapping the sea of opportunities: blockchain in supply chain and logistics", working paper, September.

Prajogo, D. and Olhager, J. (2012), "Supply chain integration and performance: the effects of long-term relationships, information technology and sharing, and logistics integration", International Journal of Production Economics, Vol.135 No.1, pp.514-522.

Preuveneers D, Joosen W, and Ilie-Zudor E. (2017), "Trustworthy data-driven networked production for customer-centric plants", Industrial Management and Data Systems, Vol.117 No.10, pp.2305-2324.

Riley, S. (2017), "How blockchain is poise to impact supply chain", Supply \& Demand Chain Executive, Vol.18 No.4, pp.24-25.

Saberi S, Kouhizadeh M, and Sarkis J. (2018), "Blockchain technology: a panacea or pariah for resources conservation and recycling?", Resources, Conservation and Recycling, Vol.130, pp.80-81.

Seidel, M.L. (2018), "Questioning centralized organizations in a time of distributed trust", Journal of Management Inquiry, Vol.27 No.1, pp.40-44.

Shanley, A. (2017), "Could blockchain improve pharmaceutical supply chain security?", Pharmaceutical Technology, pp.34-39.

Siba, T., and Prakash, A. (2016), "Block-Chain: an evolving technology", Global Journal of Enterprise Information System, Vol.8 No.4, pp.29-35.

Sklaroff, J.M. (2017), "Smart contracts and the cost of inflexibility", University Of Pennsylvania Law Review, Vol.166 No.1, pp.263-303.

Subramanian, H. (2018), "Decentralized blockchain-based electronic marketplaces", Communications of The ACM, Vol.61 No.1, pp.78-84.

Subramanian, H. and Overby, E. (2017), "Electronic commerce, spatial arbitrage, and market efficiency", Information Systems Research, Vol.28 No.1, pp.97-116.

Szabo, N. (1997). Formalizing and securing relationships on public networks. First Monday, Vol.2 No.9.

Tapscott, D. and Tapscott, A. (2016a), The Blockchain Revolution: How the technology behind Bitcoin is changing money, business, and the world, Penguin UK.

Tapscott, D. and Tapscott, A. (2016b), "The impact of blockchain goes beyond financial services", Harvard Business Review. May, pp.1-5.

Tapscott, D. and Tapscott, A. (2017), "How blockchain will change organizations", MIT Sloan Management Review, Vol.58 No.2, pp.10-13.

Tirschwell, P. (2018), "Maersk charts new future with IBM blockchain pact", Joc Online, p.1.

Tranfield, D., Denyer, D. and Smart, P. (2003), "Towards a methodology for developing evidence-informed management knowledge by means of systematic review", British Journal of Management, Vol.14, pp.207-222.

Treiblmaier, H. (2018), "The impact of the blockchain on the supply chain: a theory based research framework and a call for action", Supply Chain Management: An International Journal, Vol.23 No.6., pp.545-559.

Treiblmaier, H. and Umlauff, U. (forthcoming). Blockchain and the future of work: a selfdetermination theory approach", in: Swan, M., Potts, J., Takagi, S., Tasca, P. and Witte, F. (Eds.) Blockchain Economics: Implications of Distributed Ledger Technology.

Underwood, S. (2016), "Blockchain beyond bitcoin", Communications of The ACM, Vol.59 No.11, pp.15-17. 
Voshmgir, S. (2017), "Disrupting governance with blockchains and smart contracts", Strategic Change, Vol.26 No.5, pp.499-509.

White G.R.T. (2017), "Future applications of blockchain in business and management: a delphi study", Strategic Change, Vol.26 No.5 pp.439-451.

Yermack, D. (2017), "Corporate governance and blockchains", Review of Finance, Vol.21 No.1, pp.7-31.

Yuva, J.R. (2017), "Blockchain: next on food supply chain menu”, Food Logistics, Vol.192, pp.22-28.

Zamani E.D. and Giaglis G.M. (2018), "With a little help from the miners: distributed ledger technology and market disintermediation", Industrial Management and Data Systems, Vol.118 No.3, pp.637-652.

Ølnes, S., Ubacht, J. and Janssen, M. (2017), "Blockchain in government: benefits and implications of distributed ledger technology for information sharing", Government Information Quarterly, Vol.34 No.3, pp.355-364. 


\begin{tabular}{|c|c|c|c|c|c|c|c|}
\hline \multirow{2}{*}{\multicolumn{2}{|c|}{$\begin{array}{l}\text { BLOCKCHAIN IDENTITY } \\
\text { (REPRESENTATION) }\end{array}$}} & \multirow[b]{2}{*}{ PROPOSITIONS } & \multicolumn{4}{|c|}{ BLOCKCHAIN PROPERTIES } & \multirow[b]{2}{*}{ AUTH } \\
\hline & & & $\begin{array}{c}\text { Decentralised } \\
\text { structure }\end{array}$ & $\begin{array}{c}\text { Cryptography } \\
\text { system }\end{array}$ & $\begin{array}{l}\text { Consensus } \\
\text { mechanism }\end{array}$ & \begin{tabular}{|c|}
$\begin{array}{c}\text { Smart } \\
\text { contracts }\end{array}$ \\
\end{tabular} & \\
\hline \multirow{5}{*}{$\begin{array}{l}\text { THE ENABLING } \\
\text { BLOCKCHAIN }\end{array}$} & \multirow{5}{*}{$\begin{array}{l}\text { THE } \\
\text { BLOCKCHAIN } \\
\text { AS AN } \\
\text { INFORMATION } \\
\text { LIGHTHOUSE }\end{array}$} & $\begin{array}{l}\text { - Proposition 1a: Use of BCT in a } \\
\text { supply chain enables data } \\
\text { availability. }\end{array}$ & $\mathrm{X}$ & & & & \multirow{3}{*}{$\begin{array}{l}\text { Appelbaum and Smith (2018); Biswas et al. } \\
\text { (2017); Casado-Vara et al. (2018); Filipova } \\
\text { (2018); O’Dair and Beaven (2017); O’Leary } \\
\text { (2017); Siba and Prakash (2016); Yermack } \\
\text { (2017); Ølnes et al. (2017) }\end{array}$} \\
\hline & & $\begin{array}{l}\text { - Proposition } 1 \mathrm{~b}: \text { Use of BCT } \\
\text { enables data quality in the form } \\
\text { of data immutability. }\end{array}$ & & $\mathrm{X}$ & & & \\
\hline & & $\begin{array}{l}\text { - Proposition 1c: Use of BCT } \\
\text { enables data quality in the form } \\
\text { of data consistency. }\end{array}$ & & & $\mathrm{X}$ & & \\
\hline & & $\begin{array}{l}\text { Proposition 2: Use of BCT in a } \\
\text { supply chain enables increased } \\
\text { supply chain visibility. }\end{array}$ & $\mathrm{X}$ & & $\mathrm{X}$ & & $\begin{array}{l}\text { Arcos (2018); Dai and Vasarhelyi (2017); } \\
\text { Eljazzar et al. (2018); Filipova (2018); Koonce } \\
\text { (2016); Kshetri (2018); Leng et al (2018); } \\
\text { O’Dair and Beaven (2017); O'Leary (2017); } \\
\text { Petersen et al (2017); Subramanian (2018); } \\
\text { Tapscott and Tapscott (2016b); Underwood } \\
\text { (2016); White (2017); Yermack (2017); Ølnes } \\
\text { et al.(2017) }\end{array}$ \\
\hline & & $\begin{array}{l}\text { Proposition 3: Use of BCT in a } \\
\text { supply chain enables increased } \\
\text { supply chain traceability. }\end{array}$ & $\mathrm{x}$ & $\mathrm{X}$ & & & $\begin{array}{l}\text { Adams et al. (2017b); Biswas et al. (2017); } \\
\text { Casado-Vara et al. (2018); Clauson et al. } \\
\text { (2018); Dai et al. (2017); Filipova (2018); } \\
\text { Francisco and Swanson (2018); Hawlitschek et } \\
\text { al. (2018); Kewell et al (2017); Kim and Justl } \\
\text { (2018); Kim and Laskowski (2018); Koonce } \\
\text { (2016); Kshetri (2017); Kshetri (2018); Lacity } \\
\text { (2018); Manski (2017); Nair and Sutter (2018); } \\
\text { Nowinski and Kozma (2017); Petersen et al } \\
\text { (2017); Saberi et al. (2018); Subramanian } \\
\text { (2018); Treiblmaier and Umlauff (forth.); } \\
\text { Underwood (2016); White (2017); Yermack } \\
\text { (2017); Ølnes et al. (2017) }\end{array}$ \\
\hline
\end{tabular}




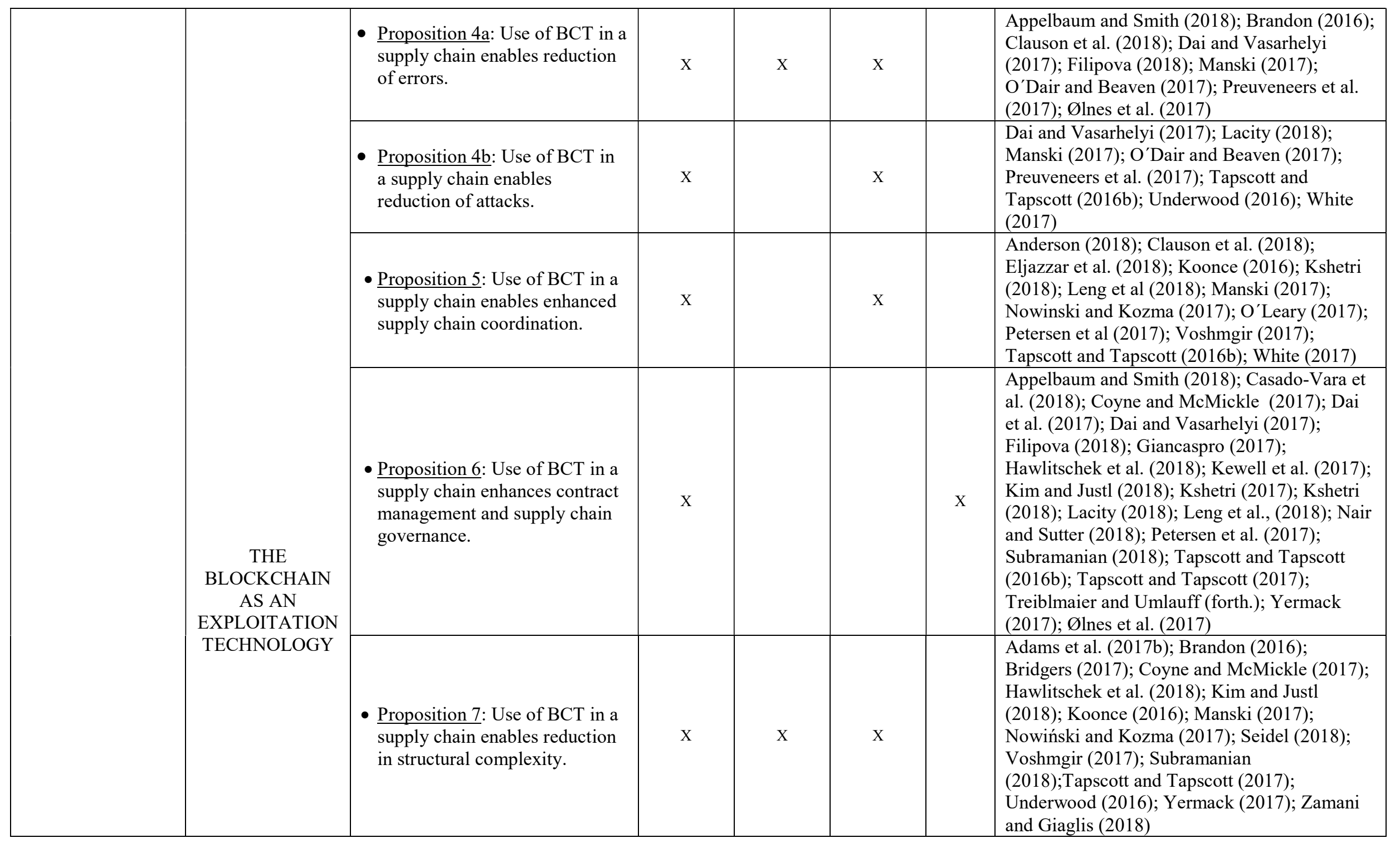




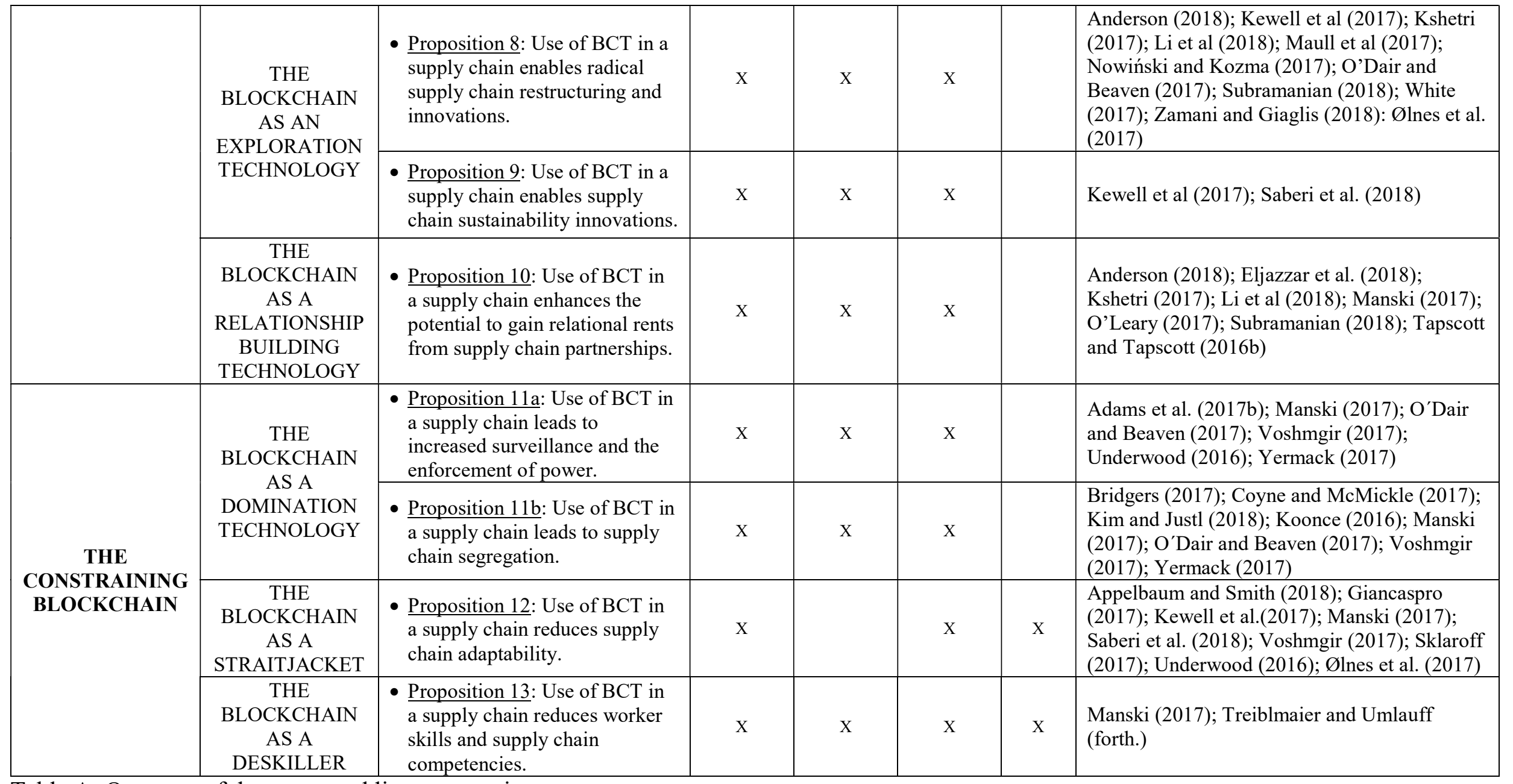

Table A: Outcome of the structured literature review 
Appendix A

\begin{tabular}{|c|c|c|c|c|c|c|c|c|}
\hline \multirow{3}{*}{$\begin{array}{l}\text { RANK ORDER LIST OF SUPPORTFOR } \\
\text { PROPOSITIONS IN SAMPLE }\end{array}$} & \multirow{3}{*}{$\begin{array}{l}\text { SUPPORT } \\
\text { IN } \\
\text { SAMPLE } \\
(\%)\end{array}$} & \multicolumn{4}{|c|}{ THE ENABLING BLOCKCHAIN } & \multicolumn{3}{|c|}{ THE CONSTRAINING BLOCKCHAIN } \\
\hline & & $\begin{array}{l}\text { INFORMATION } \\
\text { LIGHTHOUSE }\end{array}$ & $\begin{array}{l}\text { EXPLOITATION } \\
\text { TECHNOLOGY }\end{array}$ & $\begin{array}{l}\text { EXPLORATION } \\
\text { TECHNOLOGY }\end{array}$ & $\begin{array}{l}\text { RELATIONSHIP } \\
\text { BUILDING } \\
\text { TECHNOLOGY }\end{array}$ & $\begin{array}{l}\text { DOMINATION } \\
\text { TECHNOLOGY }\end{array}$ & STRAITJACKET & DESKILLER \\
\hline & & \multicolumn{7}{|c|}{ NUMBER OF PAPERS IN SAMPLE SUPPORTING THE PROPOSITION } \\
\hline $\begin{array}{l}\text { Proposition 3: Use of BCT in a supply chain } \\
\text { enables increased supply chain traceability. }\end{array}$ & $54 \%$ & 26 & & & & & & \\
\hline $\begin{array}{l}\text { Proposition 6: Use of BCT in a supply chain } \\
\text { enhances contract management and supply } \\
\text { chain governance. }\end{array}$ & $46 \%$ & & 22 & & & & & \\
\hline $\begin{array}{l}\text { Proposition 2: Use of BCT in a supply chain } \\
\text { enables increased supply chain visibility. }\end{array}$ & $33 \%$ & 16 & & & & & & \\
\hline $\begin{array}{l}\text { Proposition 7: Use of BCT in a supply chain } \\
\text { enables reduction in structural complexity. }\end{array}$ & $33 \%$ & & 16 & & & & & \\
\hline $\begin{array}{l}\text { Proposition 5: Use of BCT in a supply chain } \\
\text { enables enhanced supply chain coordination. }\end{array}$ & $27 \%$ & & 13 & & & & & \\
\hline $\begin{array}{l}\text { Proposition 8: Use of BCT in a supply chain } \\
\text { enables radical supply chain restructuring and } \\
\text { innovations. }\end{array}$ & $23 \%$ & & & 11 & & & & \\
\hline $\begin{array}{l}\text { Proposition 1a: Use of BCT in a supply chain } \\
\text { enables data availability. }\end{array}$ & $19 \%$ & 9 & & & & & & \\
\hline $\begin{array}{l}\text { Proposition } 1 \mathrm{~b}: \text { Use of BCT enables data } \\
\text { quality in the form of data immutability. }\end{array}$ & $19 \%$ & 9 & & & & & & \\
\hline $\begin{array}{l}\text { Proposition 1c: Use of BCT enables data } \\
\text { quality in the form of data consistency }\end{array}$ & $19 \%$ & 9 & & & & & & \\
\hline $\begin{array}{l}\text { Proposition 4a: Use of BCT in a supply chain } \\
\text { enables reduction of errors. }\end{array}$ & $19 \%$ & & 9 & & & & & \\
\hline $\begin{array}{l}\text { Proposition 12: Use of BCT in a supply chain } \\
\text { reduces supply chain adaptability. }\end{array}$ & $19 \%$ & & & & & & 9 & \\
\hline $\begin{array}{l}\text { Proposition 4b: Use of BCT in a supply chain } \\
\text { enables reduction of attacks. }\end{array}$ & $17 \%$ & & 8 & & & & & \\
\hline $\begin{array}{l}\text { Proposition 10: Use of BCT in a supply chain } \\
\text { enhances the potential to gain relational rents } \\
\text { from supply chain partnerships. }\end{array}$ & $17 \%$ & & & & 8 & & & \\
\hline $\begin{array}{l}\text { Proposition } 11 \mathrm{~b} \text { : Use of BCT in a supply } \\
\text { chain leads to supply chain segregation. }\end{array}$ & $17 \%$ & & & & & 8 & & \\
\hline $\begin{array}{l}\text { Proposition 11a: Use of BCT in a supply chain } \\
\text { leads to increased surveillance and the } \\
\text { enforcement of power. }\end{array}$ & $13 \%$ & & & & & 6 & & \\
\hline $\begin{array}{l}\text { Proposition 9: Use of BCT in a supply chain } \\
\text { enables supply chain sustainability } \\
\text { innovations. }\end{array}$ & $4 \%$ & & & 2 & & & & \\
\hline $\begin{array}{l}\text { Proposition } 13: \text { Use of BCT in a supply chain } \\
\text { reduces worker skills and supply chain } \\
\text { competencies. }\end{array}$ & $4 \%$ & & & & & & & 2 \\
\hline
\end{tabular}

